\title{
Embryonic skull development in the gecko, Tarentola annularis (Squamata: Gekkota: Phyllodactylidae).
}

\author{
Eraqi R. Khannoon ${ }^{1,2^{*}}$, Susan E. Evans ${ }^{3}$ \\ ${ }^{* 1}$ Biology department, College of Science, Taibah University, Al-Madinah Al- \\ Munawwarah, P.O.B 344, Kingdom of Saudi Arabia \\ ${ }^{2}$ Zoology Department, Faculty of Science, Fayoum University, Fayoum 63514, Egypt \\ ${ }^{3}$ Centre for Integrated Anatomy, Department of Cell and Developmental Biology, \\ University College London, Gower Street, London WC1E 6BT
}

Corresponding author; Eraqi R. Khannoon, email: ekhannoon@taibahu.edu.sa; err00@fayoum.edu.eg;

Keywords: Osteocranium; Development; Lizards; Paedomorphosis; Cranial morphology

\section{Highlight}

- This is the first detailed description of gekkotan skull development in a prehatching developmental series

- Our results show that ossification in most cranial elements, including cartilage bones, begins early by comparison with many other lizards. This pattern is not consistent with skeletal paedomorphosis. 


\begin{abstract}
Tarentola annularis is a climbing gecko with a wide distribution in Africa north of the equator. Herein we describe the development of the osteocranium of this lizard from the first appearance of the cranial elements up to the point of hatching. This is based on a combination of histology and cleared and stained specimens. This is the first comprehensive account of gekkotan pre-hatching skull development based on a comprehensive series of embryos, rather than a few selected stages. Given that Gekkota is now widely regarded as representing the sister group to other squamates, this account helps to fill a significant gap in the literature. Moreover, as many authors have considered features of the gekkotan skull and skeleton to be indicative of paedomorphosis, it is important to know whether this hypothesis is supported by delays in the onset of cranial ossification. In fact, we found the sequence of cranial bone ossification to be broadly comparable to that of other squamates studied to date, with no significant lags in development.
\end{abstract}




\section{Introduction}

Geckos form the largest and most diverse group of extant lizards with at least 1935 recognised species (c.25\% of all lizard taxa) and a global distribution. Seven families are recognised grouped into two main clades, Pygopodoidea (Pygopodidae, Carphodactylidae, Diplodactylidae) and Gekkonoidea (Gekkonidae, Sphaerodactylidae, Eublepharidae, Phyllodactylidae). In most morphology based phylogenies (e.g. Estes et al. 1988, Conrad 2008, Gauthier et al. 2012), Gekkota is placed within a large lizard clade, Scleroglossa, that also encompassed anguimorphs, lacertoids, scincoids, and snakes. In these molecular phylogenies (Townsend et al. 2004; Vidal \& Hedges 2009; Pyron et al. 2013; Wiens et al. 2013), Scleroglossa formed the sister group of Iguania, the latter tending to be regarded as less specialised and closer to the ancestral condition. However, molecular phylogenies have consistently found a different topology, with Gekkota not Iguania as the sister group of all other squamates (except the enigmatic Dibamidae). Molecular divergence date estimates (e.g. Vidal \& Hedges 2009; Jones et al. 2013) place the stem of Gekkota within the early Jurassic, circa 190 mya, and the origin of the crown at $\sim 105-75$ mya. The latter is consistent with the recovery of the first generally accepted gekkotans and stem-gekkotans from the Cretaceous, namely the Early Cretaceous Hoburogecko (Daza et al. 2012a, 2014) and Norellius (Conrad and Norell, 2006; Conrad and Daza, 2015) from Mongolia, unnamed taxa from the mid-Cretaceous amber of Myanmar (Daza et al. 2016), and the Late Cretaceous Gobekko (BorsukBialynicka 1990, Daza et al. 2013, 2014) from Mongolia. The Late Jurassic Eichstaettisaurus is sometimes placed as a stem-gekkotan (e.g. Gauthier et al. 2012), but it shows no definitive gekkotan characters and its positioning in the tree is not consistent 
and Eichstaettisaurus can behave as a rogue taxon in analysis (e.g. see discussion in Pyron 2017).

The gekkotan skull has been studied for more than a century in relation to its morphology (Siebenrock 1893; Noble 1921; Mahendra 1949; Hecht 1951; Webb 1951; Underwood 1954, 1957; Stephenson \& Stephenson 1956; Stephenson 1960; Kluge, 1962, 1967; Liang \& Wang 1973; Fabian-Beurmann et al., 1980; Haupl 1980; Rieppel 1984; Grismer 1988; Mohammed 1988; Abdala 1990, 1996; Daza et al. 2008, 2012b; Evans, 2008; Daza \& Bauer 2010, 2012; Bauer et al. 2018; Villa et al. 2018), evolution (Daza et al. 2012a, 2013, 2014), and biomechanics (Herrel et al. 1999, 2000; Payne et al. 2011). It is generally lightly built and somewhat depressed (Kluge 1967). It is also highly kinetic (Herrel et al. 1999, 2000), with streptostyly, mesokinesis, hypokinesis, and metakinesis (Iordansky 1990, 2011; Herrel 1999). This flexibility is enhanced by loose connective tissue between many bones (Payne et al. 2011; Vickaryous et al. 2011) and the loss of the postorbital and upper temporal bars. These losses may also be linked to the development of large eyes in this predominantly nocturnal clade (e.g. Daza \& Bauer 2010, 2012), although paedomorphosis has also been suggested for some gekkotan skull traits (e.g. Stephenson and Stephenson 1959; Stephenson 1960; Bellairs and Kamal, 1981), and peramorphosis has been reported for some groups (Daza et al., 2015). Gekkotan skulls are further characterized, in most taxa, by the development and fusion of the subolfactory processes of the frontal bone to form a cylindrical beam, by the presence of an open midparietal suture, and by the contact and often fusion of the dorsal and ventral margins of the Meckelian fossa in the lower jaw, again for strength (Evans 2008). 
Gekkotan skull development has also received attention from numerous researchers. De Beer (1937) reviewed the work of earlier embryologists, and Bellairs and Kamal (1981) provided a comprehensive review of chondrocranial development, based on the work of Kamal (1961a,b,c; 1964; 1965a,b). They also gave some consideration to dermal skull development in geckos, and this was also examined by Brock (1932: Lygodactylus, Pachydactylus), El-Toubi \& Kamal (1961a,b,c: Ptyodactylus), Rieppel (1992a: Cyrtodactylus), Wise et al. (2009, Eublepharis), and Wise and Russell (2010: circumorbital bones). However, to date, there has been no detailed description of prehatching dermatocranial development in a gekkotan, based on a full embryonic staging series.

Here we present the first comprehensive account of skull development in a phyllodactylid gekkotan, the species Tarentola annularis. T. annularis is an oviparous climbing house gecko with a snout-vent length (SVL) of $140 \mathrm{~mm}$ (Schleich et al., 1996). It has a wide distribution through Africa north of the equator. The adult skull was described by El-Toubi and Khalil (1952). An embryonic table was published recently (Khannoon, 2015), outlining eleven embryonic stages. The principal aim of the current work is to describe the pattern and sequence of cranial ossification in Tarentola annularis prior to hatching, and to compare it with the cranial ossification patterns of other squamates.

\section{Methods}

Gravid females of Tarentola annularis were collected from the field in the Fayoum region of Egypt $\left(29^{\circ} 27^{\prime} 13^{\prime \prime} \mathrm{N}, 30^{\circ} 34^{\prime} 51^{\prime \prime}\right.$ E) during April and May of 2016. This 
coincides with the breeding season. Selected gravid females were kept in the lab under conditions of temperature and humidity similar to those experienced in nature. Geckos were separated in glass or wood cages with a maximum of seven females in a cage of 90 x $40 \times 60 \mathrm{~cm}$. They were fed with insects and larvae and were provided water ad libitum. Eggs $(\mathrm{N}=76)$ were collected, placed in perlite in plastic boxes, and transferred to incubators at a constant temperature of $30 \pm 0.5^{\circ} \mathrm{C}$ and humidity $85-90 \%$. The total incubation period was 59-62 days. Embryos were extracted in phosphate buffered saline (PBS) solution and extraembryonic membranes were discarded. The embryos were then fixed in $4 \%$ paraformaldehyde (PFA) for at least $24 \mathrm{hrs}$, washed in PBS, and dehydrated using ethanol. Embryos were staged using the T. annularis embryonic table developed by Khannoon (2015). The staging criteria developed for T. annularis is consistent with those previously established for other lizards (Dufaure and Hubert, 1961; Muthukkaruppen et al. 1970; Noro et al., 2009; Wise et al., 2009). A series of embryos was selected to represent osteocranium development, with at least two embryos for each stage.

Heads of selected T. annularis embryos were dehydrated up to $95 \%$ ethanol for 5 days and transferred to acetone for three days. The ethanol-KOH-glycerol-Alizarin redAlcian blue staining protocol of Hanken and Wassersug (1981) was followed. After staining, samples were washed in distilled water, and then transferred to $1 \% \mathrm{KOH}$, and 1:3, 1:2, 1:1, 2:1, of glycerol:KOH. The stained samples were kept in 100\% glycerol. An Olympus SZH10 stereo microscope with a Rebiga 2000R camera attachment was used for capturing images.

Heads of embryos from selected embryonic stages were fixed at $4 \%$ PFA. These heads were washed after fixation using $\mathrm{dH}_{2} \mathrm{O}$ and dehydrated in ethanol (Sigma-Aldrich). 
The heads were then cleared in xylene (Sigma-Aldrich) and embedded in paraplast (Sigma-Aldrich). Samples were sectioned transversely using a Slee Cut 5062 microtome, at $7 \mu \mathrm{m}$ thickness. Sections were stained either in Masson Tri-chrome Stain or haematoxylin \& eosin (H\&E) (Humason, 1979), mounted in DPX (Sigma-Aldrich), coverslipped, and imaged using Nikon light microscope.

\section{Results}

As we were primarily interested in osteocranium development, the description begins with embryos that were already at an advanced stage of chondrocranial development. The stages are based on Khannoon (2015), with days post-oviposition (dpo) also recorded. In addition, using the comparative table provided by Ollonen et al. (2018), we have added the estimated SES stages of Werneburg (2009). Most of the descriptions that follow are based on cleared and stained whole mount specimens, but two early stages (15 dpo, 23 dpo) were examined through histological sections, and one 11 dpo embryo (stage 32) was stained as a whole mount. No ossification was seen in the 11 dpo embryo, nor in sections of the 15 dpo embryo (stage 33, SES 5). In the 11 dpo embryo, the left and right Meckel's cartilages are separate anteriorly, each ending in a curved tip that is more weakly stained than the remainder of the cartilage. In later embryos, the cartilages fuse across the midline. The term 'ossification' is used in relation to histological sections of late stage 34 where osteoblasts develop in the connective tissue during bone development. On the other hand, the term is used in all subsequent stages to describe bone stained with alizarin red stain. Nonetheless, we are aware that staining procedures for whole mount embryos may not always show the earliest stages of ossification. 


\section{Late stage 34 (23 dpo: SES 6)}

Embryos at this stage do not show obvious alizarin staining of cranial bones in whole mount specimens, but histological sections showed ossification in the lower jaw (dentary, postdentary bones), septomaxilla, nasal, frontal (including the sub-olfactory processes), parietal, vomer, pterygoid, ectopterygoid, jugal, prefrontal, postorbitofrontal, premaxilla and maxilla, and there is perichondral ossification in the shafts of the epipterygoid, quadrate, basipterygoid processes and the body of the basisphenoid (Figs 1 and 2). The premaxilla is single from first appearance. Although there was no visible ossification in the 15 dpo specimen, it seems likely that some of these elements began to ossify between 15 and 23 dpo.

\section{Late stage 35 (27 dpo: SES 7)}

Dermal ossification of the frontal and parietal was evident at this stage in the whole mount specimens (Fig.3A-C). The elements appear as paired slender bars extending along the posterodorsal edge of the eye (frontal), and the dorsolateral margins of the head to the level of the otic capsule (parietal). The tapering posterior tip of the incipient parietal curves laterally where it meets the small arched squamosal (under the interpretation of Underwood, 1957). Lateral to the frontoparietal junction is a small triangular element that represents the postorbitofrontal (usage following Daza and Bauer, 2010). This has a long frontal process and a shorter parietal process. A weakly stained maxilla can be observed anteroventral to the eyes (Fig. 3A), whereas a thick rod of dermal bone visible posteroventral to each eye represents the pterygoid (Fig. 3D). This element extends from a rostral palatine process to a caudal tip positioned on the medial 
side of the quadrate cartilage. The shafts of both the quadrate and epipterygoid are partly ossified.

The otic capsules are unossified at this stage. As noted by El-Toubi and Khalil (1952), there is a large opening in the anterolateral wall of the prootic (Fig. 3A). El-Toubi and Khalil equated this with the fenestra $\mathrm{X}$ found in some snakes (e.g. Psammophis, Al Mohammadi et al. 2019). However, in T. annularis, the opening seems to be the space between the prefacial and anterior basicapsular commissures that carries the facial nerve. In the occipital region, the posterodorsal gap between the otic capsules is occupied by a narrow cartilaginous intercapsular bridge. This corresponds to the tectum synoticum (Fig. 3C). It extends posterolaterally to form the roof of the foramen magnum, with bilateral regions of weak ossification. These ossified regions meet the occipital arches (exoccipitals) on each side ventrolaterally, with the two areas separated by strongly stained cartilage, but the occipital arches do not appear to extend on to the dorsal surface. The endolymphatic sacs lie anterodorsal to the tectum synoticum and obscure part of its anterior margin, but it is clear that no anterior process (processus ascendens) was present. On the ventral surface of the braincase, the pituitary fenestra and basicranial fenestra are open, separated by the crista sellaris. The crista sellaris is ossified, and the ossification extends along the basipterygoid processes, although their expanded tips remain cartilaginous. Ossification has also begun in the periphery of the basioccipital (Fig. 3D).

The dermal elements of the lower jaw are ossifying around Meckel's cartilage, with the articular already expanded dorsally anterior to the jaw joint and posteriorly into a retroarticular process. The left and right Meckel's cartilages have fused across the midline, but there is a small unstained central area, suggesting that fusion had only 
recently occurred.

Ventromedially, the hyoid apparatus is clearly visible with ossification beginning in the first ceratobranchials. The median element of the hyoid has a long tapering entoglossal process that runs forward within the body of the tongue (Fig. 3D).

\section{Early stage 36 (31 dpo: SES 8)}

This embryo (Fig. 4A-B) shows little advance over the previous one, and some parts are less ossified (e.g. crista sellaris). The basioccipital shows further ossification, closing the posterior part of the basicranial fenestra. In the lower jaw, ossification has progressed in all elements. Meckel's cartilage remains continuous throughout the mandible and the left and right sides have fused across the symphysis (Fig. 4A).

\section{Mid stage 36 (33 dpo: SES 8)}

The alveolar margin of the maxilla and premaxilla are visible as dense lines. The rostrodorsal process of the maxilla is developed lateral to the nasal. Teeth can be detected at both the maxilla and dentary, but are not yet implanted (Fig. 4C). Paired egg teeth are visible at the ventral edge of the premaxillary region, but they are separated from it by unstained soft tissue (Fig. 4D). Although the subolfactory processes of the frontals are developed, the frontal is still limited dorsally to a curved bar above the eye, almost making contact with the narrow parietal ossification at the posterior orbital margin (Fig. 4E). The endolymphatic sacs are deeply stained and have expanded laterally and posteriorly. In the basicranium, the pituitary and basicranial fenestrae remain open, with further ossification into the crista sellaris, the bases of the trabeculae cranii, the 
basioccipital and exoccipitals, and a little in the otic capsules, with deeply stained otoliths also visible.

\section{Early - mid stage 37 (34-36 dpo: SES 9)}

Although the skull still lacks a roof, other elements show an increased level of ossification (Fig. 5A-C). The alveolar margin of the premaxilla is ossified but the strongly mineralized egg-teeth are not implanted (Fig. 5D-E). Both the maxilla and the nasals show spreading ossification. The prefrontal is more clearly visible as a curved lamina running anterior to the eye and extending dorsally to meet the tip of the frontal. In the margin of the upper temporal fenestra, the slender squamosal is fully ossified. Its posterior tip lies adjacent to the dorsal head of the quadrate, in association with the intercalary cartilage, with all three structures 'cupped' posteriorly by the short, curved paroccipital process. The tectum of the supraoccipital remains narrow, and is ossified across its occipital border, with a small triangle of unossified cartilage at the anterior midline (Fig. 5B). There is also cartilage between the dorsal ends of the exoccipitals (occipital arches) and the tectum. It seems, therefore, that the supraoccipital in this gecko is formed only from the tectum synoticum. By $36 \mathrm{dpo}$, the stapes is partly ossified and the stapedial foramen is visible. Ossification has progressed in the prootic, in the ventral part of the anterior semicircular canal, and the lateral semicircular canal, and there is also ossification in the adjacent part of the opisthotic. The lateral prootic fenestra is gradually infilled by thin membrane bone, leaving a distinct facial foramen. In the basicranium, ossification into the dermal parasphenoid has partially closed the basicranial fenestra and there is further ossification in the margins of the basioccipital. In the lower jaw, the coronoid and the postdentary complex are strongly ossified, and the splenial has a clearly 
defined anteromedial foramen. Meckel's cartilage is still visible through the mandible up to the articular region as the sheathing dermal bone is thin, but by 36 dpo a gap has formed between the anterior and posterior parts of the cartilage (Fig. 5E). The tip of the retroarticular process remains unossified, and there is cartilage on the surfaces of the contact surfaces of the quadrate-articular joint. The endolymphatic sacs are deeply stained (Fig. 5F).

\section{Early stage 38 (41 dpo: SES 10)}

The frontals are more strongly ossified along their lateral margins, and their subolfactory processes have extended to the midline, although the frontals do not yet meet dorsally. The prefrontal is more strongly stained as an arch lying in the anterior orbital margin, anterolateral to the strengthening frontal and dorsomedial to the fully ossified maxilla (Fig. 6A). The dentary and maxillary teeth are well-mineralized, but not implanted. The supraoccipital is ossified as a single relatively narrow strip, the anterior margin of which is obscured by the enlarged endolymphatic sacs (Fig. 6B). The prootic is now almost fully ossified, except for the small alary process (Fig. 6A), and ossification is progressing in the opisthotic. Ventrally, a thin parasphenoid sheet floors the pituitary and basicranial fenestrae, but large areas of cartilage separate the otic capsule and basicranium (Fig. 6C).

In the mandible, Meckel's cartilage remains as a 'U'-shaped bridge across the symphysis, and in the more posterior parts of the dentary and postdentary complex (Fig. 6D). The hyoid apparatus is fully formed (Fig. 6C). The endolymphatic sacs have expanded laterally and posterolaterally. Ultimately they will extend through the gap between the parietal dorsally and supraoccipital ventrally (Kluge, 1967), but the parietals 
do not reach the posterior midline until after hatching.

\section{Mid-stage 38 (44-46 dpo: SES 11)}

There is little cartilage left in the skull at this stage, other than at the tips of endochondral elements and around the jaw joint and suspensorium (Fig.7A). The dentary, maxilla, and premaxilla are almost completely ossified with well-developed marginal teeth in the dentary and maxilla, and large implanted egg teeth in the premaxilla. The nasals are fully developed and meet in the midline, as do the anterior halves of the frontals. The frontal and parietal are in articulation, flanked on each side by fully developed postorbitofrontals, but a large frontoparietal fontanelle persists in the posterior half of the skull roof. The posterior tip of the squamosal is connected to the paroccipital process+intercalary by a slender thread of blue stained tissue. At 44 dpo, the paroccipital process is still cartilaginous and the intercalary is fusing to its tip (Fig.7B). The quadrate is almost fully ossified except at its dorsal head (Fig.7B,D). Ventromedially, a contact joint (syndesmosis) has formed between the pterygoid and quadrate. In the palate, the pterygoid and ectopterygoid are fully ossified, and the vomer and palatine are now visible, as are the septomaxillae (through the thin nasals). The otic capsule is fully ossified and the small alar process of the prootic is ossified, with its rostral tip in close proximity to the dorsal end of the epipterygoid, which remains cartilaginous (Fig.7A). A narrow ventral extension from the anterior arch of the prootic marks the beginning of ossification of the lateral prootic crests. The trabeculae cranii have lost their strong alcian staining and there is no evidence of an underlying parasphenoid rostrum. The endolymphatic sacs extend posteriorly and ventrolaterally into the neck, and 
anteroventrally into the cranial cavity (Fig.7D). In the lower jaw, all elements except the tip of the retroarticular process are ossified. Meckel's cartilage has regressed further (Fig.7C).

\section{Late stage 38 (48 dpo: SES 11)}

This stage shows further maturation of the osteocranium, particularly in the rostrum (Fig. $8 \mathrm{~A}, \mathrm{~B})$. The only persistent cartilage is at the tips of the retroarticular process and the epipterygoid, at the mandibular symphysis (Fig. 8C), and in the hyoid. In the premaxilla, the nasal process is well-defined, meeting the nasals and separating them for roughly half of their length. The premaxillary-maxillary joint is fully formed. The frontals are well ossified, with deeper staining in the subolfactory processes, and the anterior margin of the frontal plate is now weakly triradiate. The parietals, however, remain as narrow posterolateral bars flanking a large dorsal fenestra. The prefrontal is well-defined, as is its suture with the maxilla. The maxilla has attained its final shape, with a row of implanted teeth and evidence of secondary tooth generations visible as smaller denticles in a lateral view. In the palate, the vomers and palatines roof the oral cavity. The supraoccipital is completely ossified and exoccipitals, basioccipital, and basisphenoid are well-defined.

There is a distinct bulge behind the eye that represents the development of the jaw musculature (Fig. 8A).

\section{Late stage 38 (51-56 dpo: SES 12)}

At this stage, the skull is approaching its final hatchling condition (Fig. 9A-C). The eggteeth are expanded and anteriorly directed, but there are no traces of adult teeth on the 
premaxilla. The teeth in the maxilla and dentary are implanted (Fig. 9A). The basipterygoid processes are more prominent (Fig. 9C), and the occipital region has fully ossified around the foramen magnum. The otic capsules are also fully ossified, and the endolymphatic sacs have enlarged and spread into the neck as well as the braincase (Fig.10A). The only remnant of Meckel's cartilage is across the mandibular symphysis.

\section{Late stage 39 (61 dpo: SES 13)}

The skull has attained its final hatchling form (Fig.10B-D). All skull elements are articulated with neighbouring bones, the teeth are widely spaced and firmly implanted, and the paired egg teeth appear longer and broader (Fig.10A). They are now flanked by small adult premaxillary tooth germs. The frontals cover three-quarters of the interorbital skull, but their margins splay out posteriorly to meet the parietals. The parietal remain as narrow bars flanking the posterodorsal part of the head. They do not yet meet in the posterior midline, leaving a large open parietal fontanelle across the width of the head at hatching (Fig.10B).

\section{Discussion}

\section{a) Timing of ossification}

Although there have been several accounts of embryo development in gekkotans, these have focused on external features (e.g. Noro et al. 2009; Wise et al. 2009; Khannoon 2015), on the chondrocranium alone (El-Toubi and Kamal 1961a,b; Kamal, 1961a-c, 1964, 1965a,b ), or on limited stages in skull development (Brock 1932; El-Toubi and 
Khalil, 1952; El-Toubi and Kamal 1961c; Rieppel, 1992; Daza et al., 2013). By contrast, descriptions of pre-hatching skull development exist for a wide range of other squamates, including scincids (e.g. Hugi et al. 2010; Jerez et al., 2015), lacertids (e.g. Rieppel 1994), amphisbaenians (Montero et al. 1999), teiids (Arias and Lobo, 2006), gymnophthalmids (Hernandez-Jaimes et al. 2012; Roscito and Rodrigues, 2012), iguanians (Lobo et al. 1995; Abdala et al. 1997; Alvarez et al. 2005; Ollonen et al., 2018), anguids (Good, 1995), varanids (Werneberg et al. 2015), and snakes (e.g. Jackson 2002; Boughner et al. 2007; Al Mohammadi et al. 2019).

However, as the accounts differ from one another in the number of stages analysed, and therefore in the degree of resolution offered, it can therefore be difficult to compare the order of appearance of individual elements precisely. Two ossification stages were reported for Amphisbaena (Montero et al. 1999), with three for Ptychoglossus (Hernandez-Jaimes et al. 2012), four for Salvator (Tupinambis) (Arias and Lobo 2006), seven for Varanus (Werneburg et al. 2015), and eight for Elgaria (Good, 1995) and Polychrus (Alvarez et al. 2005). Similarly, published accounts use different methods of staging. In some cases, these can be aligned (Ollonen et al. 2018), but this is not possible when the staging is based only on embryo size. In Tarentola, we recorded three stages at which new ossification centres appeared, although this is probably because we were unable to sample specimens between 15dpo and 23dpo. At 15 dpo (stage 33) histological sections showed no evidence of ossification, but by 23 dpo (late stage 34), most of the dermal bones and several of the cartilage bones already showed the beginning of ossification. Some of the elements most strongly ossified at late stage 34 (e.g. pterygoid, lower jaw) probably began ossification earlier in stage 34 than the others. 
Table 1 compares ossification stages (Dufaure and Hubert 1961) in Tarentola with those lizards for which comparable data is available.

In general, the cranial ossification sequence in Tarentola is similar to that of other squamates. As in most squamates studied, the ossification in the dermal bones preceded that of most cartilage bones, with the prootic and opisthotic among the last to ossify. We found no evidence that ossification in Tarentola lagged behind that of other squamates; in many cases, ossification began earlier (Table 1).

More details of individual skull regions are outlined below, focusing on areas of interest discussed in previous literature.

\section{b) Skull roof}

The skull roof of $T$. annularis completes its ossification in two distinct parts. The rostral part (nasals and most of the frontals) is well advanced by hatching, with the nasals fully formed and the frontals meeting dorsally and ventrally (subolfactory processes) for almost three-quarters of their length. The posterior skull, from the back of the orbits to the occipital region, remains largely unroofed with the parietals persisting as thin bars on either side of a large parietal fontanelle. This delayed ossification has been proposed as a gekkotan trait (El-Toubi \& Kamal, 1961c), linked to paedomorphosis, but Maisano's (2001) study of hatchling squamate skulls showed it to be highly variable across families.

A large parietal fontanelle was present in a hatchling of the sphaerodactylid gecko Gonatodes albogularis, but also in the anguid Elgaria coerulea, the scincid Eumeces fasciatus, the xantusiid Xantusia henshawi, and several lacertids, whereas the gekkonids Bunopus tuberculatus, Cyrtodactylus pubisulcus, and Hemidactylus homoeolepis were 
among the species with the most fully ossified parietal at hatching.

\section{c) The circumorbital bones}

Anteriorly, the orbit is framed only by the prefrontal in $T$. annularis. There is no indication of a lachrymal bone, an element absent in most gekkotans (Webb, 1951), but recorded as present in some eublepharids (Eublepharis macularius, Coleonyx variegatus) and the gekkonid Pachydactylus bicolor (Daza and Bauer 2010; Griffing et al. 2017).

There is a single bone in the posterodorsal margin of the orbit in most gekkotans (reportedly absent in Lygodactylus, Daza and Bauer 2010). The homology of this element has been the subject of discussion by many previous researchers. Fossil stem-gekkotans are reported to possess both a postfrontal and a postorbital bone (e.g. Daza et al. 2016), as in rhynchocephalians and most extant lizards. Some researchers (e.g. El-Toubi and Khalil, 1952; El-Toubi and Kamal, 1961c) concluded that the single bone in extant gekkotans is the postfrontal, with the postorbital having been lost, or absorbed by the

postfrontal (Siebenrock 1895) during evolution. In contrast, based on their examination of embryo development in the leopard gecko, Eublepharis macularius, Wise and Russell (2010) concluded that the single bone in gekkotans is the postorbital. They recorded separate ossification centres in the lateral and posterior margins of the orbit. A long slender anterior centre, identified by Wise and Russell (2010) as the postfrontal, formed along the orbital margin of the frontal and subsequently fused with it, leaving the second, proposed postorbital centre, as the adult bone. However, it is also possible that the sliverlike ossification identified by these authors as the postfrontal is a neomorph in the fibrous supraorbital fascia, analogous to the parafrontal bones of some sphaerodactylid gekkotans 
(Griffing et al. 2017).

In T. annularis, there is a triangular bone in the posterodorsal corner of the orbit. This was single from its first appearance (stage 34). The bone has a narrow shaft-like apical process, directed anteriorly, that lies parallel to, and in close proximity with, the orbital margin of the frontal. The base of the bone is arched and lies a short distance from the parietal. Given the uncertainty as to whether this could be single postfrontal, a postorbital, or a fusion of the two, we have followed Daza and Bauer (2010) in using the term postorbitofrontal. This is intended to denote uncertainty with respect to the homologies of this element, rather than implying it is compound.

Unlike the majority of lizards, no extant gekkotan has a complete jugal arch, although many have a ligament connecting the postorbitofrontal to the posterior end of the maxilla. Reduction of the jugal arch has been linked to the increase in eye size in gekkotans (Daza and Bauer 2010, 2012). Nonetheless, most or all gekkotans retain remnants of the jugal in the ventral orbital margin (El-Toubi and Kamal, 1961c; Kluge 1967; Daza and Bauer 2010), although it is reportedly fused to the ectopterygoid in the pygopodid Lialis (Daza and Bauer 2010). The jugal remnant gives attachment to the adductor mandibulae superficialis jugalis (Daza and Bauer 2010) that runs between the postorbitofrontal and jugal to close the posterior margin of the orbit. In T. annularis, the adult jugal is a thin sliver lying dorsomedial to the orbital process of the maxilla. It is visible in the histological sections from stage 34 (dpo 23).

\section{d) Upper jaw}

The gekkotan premaxilla can be single, paired, or partially fused at the egg-tooth stage. 
According to Kluge (1967), paired premaxillary centres of ossification are found only in eublepharid and diplodactylid gekkotans. In $T$. annularis, the premaxilla was single from its first appearance, in agreement with the observations of El-Toubi and Kamal (1961c).

\section{e) Quadrate suspension}

In most lizards, two bones support the quadrate - an outer squamosal and an inner supratemporal. In most gekkotans, there is only one. Although Camp (1923) identified this as the supratemporal, Underwood (1957) demonstrated that it is the squamosal. Some eublepharid geckos (e.g. Aeluroscalabotes felinus, Eublepharis macularius) and some gekkonids (e.g. Tropiocolotes helenae, Cryptactites peringueyi) retain two bones in this position (Daza et al. 2011), a small medial one (supratemporal) and a larger lateral one (squamosal). Most authors now agree that the single bone retained in the majority of gekkotans is the squamosal. Only one element is represented in the developing skull of $T$. annularis and this must be interpreted as a squamosal.

However, the gekkotan squamosal has a variable role in quadrate suspension (e.g. Daza et al. 2008, 2012b; Daza and Bauer 2012), and has been lost in some miniaturised taxa (e.g. the pygopodid Aprasia repens, Daza et al. 2008). Instead, the quadrate often has a stronger articulation with the oto-occipital (paroccipital abutting), and Payne et al. (2011) reported that the quadrate-oto-occipital joint in T. annularis was a synchondrosis.

In our samples, we found that the intercalary cartilage initially lay between the head of the quadrate, the tip of the squamosal, and the short curved paroccipital process. The intercalary appeared to fuse with the paroccipital process, but that component remained cartilaginous (at least up to hatching) when the remainder of the paroccipital ossified. 
Fusion to the paroccipital process was one of the fates of the intercalary discussed by Bellairs and Kamal (1981, p.34), with Lacerta cited as a possible example, but they also acknowledged a lack of clarity in the literature and accepted that there might be variation between taxa. The tip of the squamosal was connected to the intercalary by a thread of unmineralised tissue.

We also found no evidence of the laminar element reported by some authors as lying along the lateral edge of the quadrate in some taxa (El-Toubi \& Kamal 1961c; Daza and Bauer, 2012). Although El-Toubi and Kamal identified this as a possible remnant quadratojugal, it is more likely to be mineralized ligament or fascia (Evans 2008, Daza and Bauer 2012).

\section{f) Braincase}

Bellairs and Kamal (1981) reported that although Sphenodon has only a tectum synoticum, they considered the tectum of most lizards (listing lacertids, agamids, and geckos) to be a combination of tectum synoticum and tectum posterius. However, in Tarentola annularis, we were unable to confirm that the occipital arches contributed to the tectum, suggesting that the narrow tectum of this species may be only tectum synoticum. As recorded by Bellairs and Kamal (1981), there was no evidence of an ascending process on the tectum of Tarentola annularis.

Kamal (1965) reported the presence of the snake fenestra X in Tarentola mauritanica, but it seems likely that what he reported was the opening between the prefacial commissure and anterior basicapsular commissure that gives passage to, and ultimately encloses, the facial nerve foramen. This is not homologous to the fenestra $\mathrm{X}$ of snakes, through which nothing passes (Bellairs and Kamal, 1981). 


\section{g) Egg-teeth}

In T. annularis a pair of egg teeth appears as early as marginal tooth development. These teeth are highly mineralized, but they remain separated from the alveolar margin of the premaxilla until stage 38 (51 dpo: SES 12). There are no adult teeth on the premaxilla until just before hatching at stage 39 (61 dpo: SES 13). The possession of paired egg teeth is a characteristic feature of gekkotans and dibamids (Camp, 1923), and is also considered to represent the primitive squamate condition (De Beer, 1949; Edmund 1969). Other squamates have a single median egg tooth (Edmund, 1969; Fons et al., 2019; Hermyt et al. 2020), but this can arise in different ways. In snakes, a single egg tooth can arise from the fusion of paired adjacent tooth germs during early embryonic stages (Fons et al., 2019), but in lizards, a median egg-tooth can result from the degeneration of one of an original pair of egg teeth or from a single median tooth germ (De Beer, 1949; Hermyt et al. 2020). The egg tooth or teeth are lost a few days post hatching, and replaced by adult premaxillary teeth (Trauth, 1988). A single median egg tooth also exists in crocodiles, turtles and birds, as well as titanosaurian dinosaurs (Garcia, 2007), but it has an integumental origin (De Beer, 1949; Clark, 1961), in contrast to the real egg teeth of squamates that are formed of dentine and enamel. Interestingly, the egg tooth of the tuatara, Sphenodon, is also an integumentary caruncle (De Beer, 1949), so the possession of fully mineralized egg-teeth is a squamate rather than lepidosaurian character.

\section{h) Mandible}

In $T$. annularis, the left and right Meckel's cartilages were found to be unfused in the 11 dpo embryo (stage 32), but had fused across the anterior midline by 27 dpo (stage 35). 
Symphysial fusion of this kind is a character of gekkotans and iguanians, and has been associated with specialized tongue actions (Holliday et al. 2010). Holliday et al. (2010) suggest the fusion of the cartilages across the symphysis may constrain the joint to some degree, providing a more secure platform for the action of the genioglossus muscle during lingual feeding and drinking.

\section{i) Endolymph}

Calcified (alizarin-stained) endolymph was recorded in an embryo of 11 dpo (stage 32: SES 4) in which there was no trace of ossification in any part of the skull. The greatest expansion of the endolymph occurs through stage 38 (dpo 41-46), at which time the sacs extend out into the dorsum and sides of the neck as well as internally towards the anterior end of the cranial cavity.

\section{Conclusions}

The pre-hatching osteocranial development of a gekkotan lizard (Tarentola annularis) is described for the first time. We found no evidence of a lachrymal bone at any stage of development, nor of a quadratojugal, and the postorbitofrontal and premaxilla were observed to have a single centre of ossification from the outset. The jugal appears early but remains vestigial throughout development, forming a small splint in the lower orbital margin in adults. However, it is present early in development, at the same time as most other dermal bones, so the reduced size does not appear to be due to a developmental delay. Meckel's cartilage is unfused at the mandibular symphysis at stage 32 , but has fused across the symphysis by stage 34 . Gekkota is now widely considered to represent 
the sister group of all other squamates (other than perhaps the secretive and poorly known dibamids). Nonetheless, the timing and sequence of ossification in Tarentola was found to be broadly similar to that of other squamates described to date. We also found no significant delay in the onset of cranial ossification that might correlate with paedomorphosis.

\section{Acknowledgements}

Our thanks to Dr Yoshiyuki Yamamoto (UCL) for the use of his stereo-microscope and camera to image the embryos, and to Dr Juan Daza (Sam Houston State University) and an anonymous reviewer for their helpful comments on an earlier version of the manuscript.

\section{References}

Abdala V (1990) Descripción osteologíca de Homonota horrida (Sauria Gekkonidae). Acta Zoo Lilloana 39, 31-38.

Abdala V (1996) Osteología craneal y relaciones de los geconinos sudamericanos (Reptilia: Gekkonidae). Rev Esp Herpetol 10, 41-54.

Abdala F, Lobo F, Scroochi G (1997) Patterns of ossification in the skeleton of Liolaemus quilmes (Iguania: Tropiduridae). Amphibia-Reptilia 18, 75-83.

Al Mohammadi GA, Khannoon ER, Evans SE (2019) The development of the osteocranium in the snake Psammophis sibilans (Serpentes: Lamprophiidae). $J$ Anat 236 (1), 117-131. doi: 10.1111/joa.13081. 
Alvarez BB, Lions ML, Calamante C (2005) Biologia reproductive y desarrollo del esqueleto de Polychrus acutirostris (Iguania, Polychrotidae). FACENA 21, 3-27.

Arias F, Lobo F (2006) Patrones de osificacion en Tupinambis merianae y Tupinambis rufescens (Squamata: Teiidae) y patrones generals en Squamata. Cuadernos Herpetol 20, 3-23.

Bauer AM, Beach-Mehrotra M, Bermudez Y, Clark GE, Daza JD, Glynne E, Hagyari D, Harnden JM, Holovacs N, Kanasiro A, Lofthus AJ, Pierce ZW, Aaliyah R, Syed Samreena M, Vallejo-Pareja C, Walker BA, Willett J (2018) The tiny skull of the Peruvian Gecko Pseudogonatodes barbouri (Gekkota: Sphaerodactylidae) obtained via a divide-and-conquer approach to morphological data acquisition. $S$ Am J Herpetol 13, 102-116.

Bellairs Ad'A, Kamal AM (1981) The chondrocranium and the development of the skull in recent reptiles. In: Gans C, Parsons TS (eds). Biology of the Reptilia. Volume 11. New York: Academic Press. 1-263.

Borsuk-Białynicka M (1990) Gobekko cretacicus gen. et. sp. n., a new gekkonid lizard from the Cretaceous of the Gobi Desert. Acta Palaeontol Pol 35: 67-76.

Boughner JC, Buchtová M, Fu K, Diewert V, Hallgrímsson B, Richman J M (2007) Embryonic development of Python sebae - I: Staging criteria and macroscopic skeletal morphogenesis of the head and limbs. Zoology, 110, 212-230.

Brock GT (1932) Some developmental stages in the skulls of the geckos, Lygodactylus capensis and Pachydactylus maculosa, and their bearing on certain important problems in lacertilian craniology. S Afr J Sci 29, 508-532. 
Camp CL (1923) Classification of lizards. B Am Mus Nat Hist 48(11), 289-480.

Clark GA (1961) Occurrence and timing of egg teeth in birds. Wilson Bull 73(3), 268278.

Conrad JL (2008) Phylogeny and systematics of Squamata (Reptilia) based on morphology. B Am Mus Nat Hist 310, 1-182.

Conrad JL, Daza JD (2015) Naming and rediagnosing the Cretaceous gekkonomorph (Reptilia, Squamata) from Öösh (Övörkhangai, Mongolia). J Vertebr Paleontol 35, 5 DOI: 10.1080/02724634.2015.980891.

Conrad JL, Norell MA (2006) High-resolution X-ray computed tomography of an Early Cretaceous gekkonomorph (Squamata) from Öösh (Övorkhangai; Mongolia). Hist Biol 18, 405-431.

Daza JD, Abdala V, Thomas R, Bauer AM (2008) Skull anatomy of the miniaturized gecko Sphaerodactylus roosevelti (Squamata: Gekkota). J Morphol 239, 13401364.

Daza JD, Bauer AM (2010) The circumorbital bones of the Gekkota (Reptilia: Squamata). Anat Rec 293 (3), 402-413.

Daza JD, Bauer AM (2012) Temporal bones of the Gekkota support molecular relationships within the Pygopodoidea. J Herpetol 46 (3), 381-386.

Daza JD, Diogo R, Johnston P, Abdala V (2011) Jaw adductor muscles across lepidosaurs: a re-appraisal. Anat Rec 294, 1765-1782.

Daza JD, Alifanov VR, Bauer AM (2012a) A redescription and phylogenetic reinterpretation of the fossil lizard Hoburogekko suchanovi Alifanov, 1989 
(Squamata, Gekkota), from the Early Cretaceous of Mongolia. J Vertebr Paleontol 32, 1303-1312.

Daza JD, Aurich J, Bauer AM (2012b) Anatomy of an enigma: an osteological investigation of the Namibian festive gecko (Narudasia festiva: Gekkonidae: Gekkota). Acta Zool 93, 465-486.

Daza JD, Bauer AM, Snively E (2013) Gobekko cretacicus (Reptilia: Squamata) and its bearing on the interpretation of gekkotan affinities. Zool J Linn Soc-Lond 167, $430-448$.

Daza JD, Bauer AM, Snively ED (2014) On the fossil record of the Gekkota. Anat Rec 297, 433-462.

Daza JD, Mapps AA, Lewis PJ, Thies ML, Bauer AM (2015) Peramorphic traits in the tokay gecko skull. J Morphol 267, 915-928. (doi:10.1002/jmor.20389)

Daza JD, Stanley EL, Wagner P, Bauer AM, Grimaldi DA (2016) Mid-Cretaceous amber fossils illuminate the past diversity of tropical lizards. Science Advances 4;2(3):e1501080.

De Beer GR (1937) The Development of the Vertebrate Skull. Clarendon Press, Oxford.

De Beer GR (1949) Caruncles and egg-teeth: some aspects of the concept of homology. $P$ Linn Soc Lond 161, 218-224.

Dufaure JP, Hubert J (1961) Table de développement du lézard vivipare-Lacerta (Zootoca) vivipara Jacquin. Arch Anat Microsc Mo 50, 309-328.

Edmund AG (1969) Dentition. In: Gans C, ed. Biology of the Reptilia Morphology A. Vol 1. London, UK: Academic Press. Pp.117-200. 
El_Toubi MR, Kamal AM (1961a) The development of the skull of Ptyodactylus hasselquistii. I. The development of the chondrocranium, J Morphol, 108, 63-94.

El_Toubi MR, Kamal AM (1961b) The development of the skull of Ptyodactylus hasselquistii. II. The fully formed chondrocranium, J Morphol 108, 165-191.

El_Toubi MR, Kamal AM (1961c) The development of the skull of Ptyodactylus hasselquistii. III. The osteocranium of a late embryo, J Morphol 108, 193-202.

El-Toubi MR and Khalil A (1952) The cranial osteology of Egyptian geckos. Bulletin de l'Institut Fouad 1er du Desert 2, 84-110.

Estes R, De Queiroz, K, Gauthier JA (1988) Phylogenetic relationships within Squamata. In, Estes R, and Pregill G (eds), Phylogenetic Relationships of the Lizard Families. Essays commemorating Charles L Camp. Stanford; Stanford University Press, 119-282.

Evans SE (2008) The skull of lizards and tuatara. In: C Gans, AS Gaunt, K Adler, eds. Biology of the Reptilia, Vol. 20, Morphology H. Ithaca: Society for the Study of Amphibians and Reptiles. p 1- 347.

Fabián-Beurmann ME, Ibarra-Vieira M, Alves MLM (1980) Estudo osteológico comparativo do cranio de Hemidactylus mabouia (Morreau de Jonnes, 1818) e Homonota uruguayensis (Vaz Ferreira \& Sierra de Soriano, 1961) (Lacertilia, Gekkonidae). Rev Bras Biol 40, 187-202.

Fons JM, Gaete M, Zahradnicek O, Landova M, Bandali H, Khannoon ER, Richman JM, Buchtova M, Tucker AS (2019) Getting out of an egg: merging of tooth germs to create an egg tooth in the snake. Dev Dynam 249(2), 199-208. 
doi.org/10.1002/dvdy.120

García RA (2007) An 'egg-tooth'-like structure in titanosaurian sauropod embryos. $J$ Vertebr Paleontol 27(1), 247-252.

Gauthier JA, Kearney M, Maisano JA, Rieppel O, Behlke ADB (2012) Assembling the squamate tree of life: perspectives from the phenotype and the fossil record. $B$ Peabody Mus Nat Hi 53, 3-308.

Griffing AH, Daza JD, DeBeer JC, Bauer AM (2017) Developmental osteology of the parafrontal bones of Sphaerodactylidae. Anat Rec 301, 581-606.

Grismer LL (1988) Phylogeny, taxonomy, classification, and biogeography of eublepharid geckos. In: Estes R, Pregill G, editors. Phylogenetic Relationships of the Lizard Families. Essays commemorating Charles L Camp. Stanford, California: Stanford University Press. pp 369-469.

Hanken J, Wassersug RJ (1981) The Visible Skeleton. Functional Photography 16, 2226.

Haüpl VM (1980) Das Schädelskelett einiger Arten der Fam.Gekkonidae. Annalen Naturhistorisches Museums in Wien 83, 479-518.

Hecht MK (1951) Fossil lizards of the West Indian genus Aristelliger (Gekkonidae). Am Mus Novit 1538, 1-33.

Hermyt M, Janiszewska K, Rupik W (2020) Squamate egg tooth development revisited using three-dimensional reconstructions of brown anole (Anolis sagrei, Squamata, Dactyloidea) dentition. J Anat, online https://doi.org/10.1111/joa.13166.

Hernandez-Jaimes C, Jerez A, Ramirez-Pinilla MP (2012) Embryonic development of the 
skull of the Andean lizard Ptychoglossus bicolor (Squamata, Gymnophthalmidae). J Anat 221, 285-302.

Herrel A, de Vree F, Delheusy V, Gans C (1999) Cranial kinesis in gekkonid lizards. J Exp Biol 202, 3687-3698.

Herrel A, Aerts P, De Vree F (2000) Cranial kinesis in geckoes: Functional implications. J Exp Biol 203, 1415-1423.

Holliday CM, Gardner NM, Paesani SM, Douthitt M, and Ratliff JL (2010) Microanatomy of the mandibular symphysis in lizards: patterns in fiber orientation and Meckel's Cartilage and their significance in cranial evolution. Anat Rec 293, 1350-1359.

Hugi J, Mitgutsch C, Sanchez-Villagra MR (2010) Chondrogenic and ossification patterns and sequences in White's skink Liopholis whitii (Scincidae, Reptilia). Zoosyst Evol 86, 21-32.

Iordansky NN (1990) Evolution of cranial kinesis in the lower tetrapods. Neth J Zool 40, $32-54$.

Iordansky NN (2011) Cranial kinesis in lizards (Lacertilia): origin, biomechanics, and evolution. Biol Bull 38(9), 852-861.

Jackson K (2002) Post-ovipositional development of the Monocled cobra, Naja kaouthia (Serpentes: Elapidae). Zoology 105(3), 359-367.

Jerez A, Sanchez-Martinez PM, Guerra-Fuentes RA (2015) Embryonic skulls development in the neotropical viviparous skink Mabuya (Squamata: Scincidae). Acta Zool Mexicana (n.s.) 31, 391-402. 
Jones MEH, Anderson CL, Hipsley CA, Müller J, Evans SE, Schoch RS (2013) Integration of molecules and new fossils supports a Triassic origin for Lepidosauria (lizards, snakes, and tuatara). BMC Evol Biol 13: 208 doi:10.1186/1471-2148-13-208.

Kamal AM (1961a) The chondrocranium of Hemidactylus turcicus. Anat Anzeiger 109, 89-108.

Kamal AM (1961b) The common characters of the gekkonid chondrocranium. Anat Anzeiger 109, 109-113.

Kamal AM (1961c) The phylogenetic position of the Geckonidae in the light of the developmental study of the skull. Anat Anzeiger 109, 114-116.

Kamal AM (1964) Notes on the chondrocranium of the gecko, Tropiocolotes steudneri. Bulletin of the Zoological Society of Egypt 19, 73-83.

Kamal AM (1965a) The chondrocranium of the gecko Stenodactylus stenodactylus. Proceedings of the Egyptian Academy of Sciences 18, 59-69.

Kamal AM (1965b) Observations on the chondrocranium of Tarentola mauretanica. Proceedings of the Egyptian Academy of Sciences 19, 1-9.

Kluge AG (1962) Comparative osteology of the eublepharid genus Coleonyx Gray. J Morphol 110, 299-332.

Kluge AG (1967) Higher taxonomic categories of gekkonid lizards and their evolution. $B$ Am Mus Nat Hist 135, 1-60.

Khannoon ER (2015) Developmental stages of the climbing gecko Tarentola annularis with special reference to the claws, pad lamellae, and subdigital setae. $J$ Exp Zool 
B 324, 450-464.

Liang Y-S, Wang C-S (1973) Comparative study of osteology on the house geckos, Hemidactylus bowringii (Gray) and Hemidactylus frenatus Duméril \& Bibron from Taiwan. Fu Jen Studies in Natural Science 7, 63-123.

Lobo F, Abdala F, Scrocchi GJ (1995) Desarrollo del esqueleto de Liolaemus scapularis (Iguania: Tropiduridae). Bollettino del Museo Regionale di Scienze Naturali Torino 13, 77-104.

Mahendra BC (1949) The skull of the Indian house-gecko. Hemidactylus flaviviridis Rüppell. Proceedings of the Zoological Society of Bengal 2, 29-42.

Maisano JA (2001) A survey of the state of ossification in neonatal squamates. Herpetol Monogr 15, 135-157.

Mohammed MBH (1988) Comparative osteology of three gecko lizards of the genus Stenodactylus (Reptilia: Gekkonidae). Zool Anzeiger 221, 435-447.

Montero R, Gans C, Lions ML (1999) Embryonic development of the skeleton of Amphisbaena darwini heterozonata (Squamata: Amphisbaenidae) J Morphol 239, $1-25$.

Muthukkaruppan VR, Kanakambika P, Manickavel V, Veeraraghavan K (1970) Analysis of the development of the lizard Calotes versicolor. 1. A series of normal stages in the embryonic development. J Morphol 130, 479-490.

Noble GK (1921) The bony structure and phyletic relations of Sphaerodactylus and allied lacertilian genera, with the description of a new genus. Am Mus Novit 4, 1-16.

Noro M, Uejima A, Abe G, Manabe M, Tamura K (2009) Normal developmental stages 
of the Madagascar Ground gecko Paroedura pictus with special reference to limb morphogenesis. Dev Dyn 238, 100-109.

Ollonen J, Da Silva FO, Mahlow K, Di-Poi N (2018) Skull development, ossification pattern, and adult shape in the emerging lizard model organism Pogona vitticeps: a comparative analysis with other squamates. Front Physiol 9: 278. doi:10.3389/fphys.2018.00278.

Payne SL, Holliday CM, Vickaryous MK (2011) An osteological and histological investigation of cranial joints in geckos. Anat Rec 294, 399- 405.

Pyron RA, Burbrink FT, JJ Wiens (2013) A phylogeny and updated classification of Squamata, including 4161 species of lizards and snakes. BMC Evol Biol 13: 93. https://doi.org/10.1186/1471-2148-13-93.

Pyron RA. (2017). Novel approaches for phylogenetic inference from morphological data and total-evidence dating in squamate reptiles (lizards, snakes, and amphisbaenians). Syst. Biol. 66: 38-56.

Rieppel O (1984) The structure of the skull and jaw adductor musculature of the Gekkota, with comments on the phylogenetic relationships of the Xantusiidae (Reptilia: Lacertilia). Zool J Linn Soc-Lond 82, 291-318.

Rieppel O (1992) Studies on skeleton formation in reptiles. I. The postembryonic development of the skeleton in Cyrtodactylus pubisulcus (Reptilia: Gekkonidae). Journal of Zoology 227(7), 87-100.

Rieppel O (1994) Studies on skeleton formation in reptiles: patterns of ossification in the skeleton of Lacerta agilis exigua Eichwald (Reptilia, Squamata). J Herpetol 28 
(2), 145-153.

$\underline{\text { Roscito JG, Rodrigues }}$ MT (2012) Skeletal development in the fossorial gymnophthalmids Calyptommatus sinebrachiatus and Nothobachia ablephara. Zool 115(5), 289-301. doi.org/10.1016/j.zool.2012.02.004.

Siebenrock F (1893) Das Skelet von Uroplatus fimbriatus Schneid. Annalen Naturhistorisches Museums in Wien 8, 517-536.

Stephenson NG, Stephenson EM (1956) The osteology of the New Zealand geckos and its bearing in their morphological status. T Roy Soc NZ 84, 341-358.

Stephenson NG (1960) The comparative osteology of the Australian geckos and its bearing on their morphological status. Z J Linn Soc 44, 278-299.

Townsend TM, Larson A, Louis E, Macey JR (2004) Molecular phylogenetics of Squamata: The position of snakes, amphisbaenians, and dibamids, and the root of the squamate tree. Syst Biol 53, 735- 757.

Trauth SE (1988) Egg tooth development and morphology in the Six-lined Racerunner, Cnemidophorus sexlineatus (Sauria: Teiidae), using Scanning Electron Microscopy. J Arkansas Acad Sci 42, 84-85.

Underwood G (1954) On the classification and evolution of geckos. P Zool Soc Lond $124,469-492$.

Underwood G (1957) On lizards of the family Pygopodidae. A contribution to the morphology and phylogeny of the Squamata. J Morphol 100, 207-268.

Vickaryous MK, Holliday CM, Payne SL (2011) An osteological and histological investigation of cranial joints in geckos. J Anat 294(3), 399- 405. 
Vidal N, Hedges SB (2009) The molecular evolutionary tree of lizards, snakes, and amphisbaenians. CR Biol 332, 129-139.

Villa A, Daza JD, Bauer AM, Delfino M (2018) Comparative cranial osteology of European gekkotans (Reptilia, Squamata). Z J Linn Soc 184, 857-895.

Webb M (1951) The cranial anatomy of the South African geckoes Palmatogecko rangei (Andersson) and Oedura karroica (Hewitt). Annals of the University of Stellenbosch 27A, 131-165.

Werneburg I (2009) A standard system to study vertebrate embryos. PLoS ONE 4:e5887. doi: 10.1371/journal.pone.0005887.

Werneburg I, Polachowski KM, Hutchinson MN (2015). Bony skull development in the Argus monitor (Squamata, Varanidae, Varanus panoptes) with comments on developmental timing and adult anatomy. Zoology 118, 255-280.

Wiens JJ, Hutter CR, Mulcahy DG, Noonan BP, Townsend TM, Sites JW, Reeder TW (2012) Resolving the phylogeny of lizards and snakes (Squamata) with extensive sampling of genes and species. Biol Letters 8, 1043-1046.

Wise PAD, Vickaryous M, Russell AP (2009) An embryonic staging table for in ovo development of Eublepharis macularius, the leopard gecko. Anat Rec 292, 1198 1212.

Wise PAD, Russell A (2010) Development of the dorsal circumorbital bones in the Leopard Gecko (Eublepharis macularius) and its bearing on the homology of these elements in the Gekkota. Anat Rec 293, 2001-2006. 


\section{Figure captions}

Figure 1. Tarentola annularis. Histological sections through a late stage 34 (23 dpo) embryo. A) nasal region; B) anterior eye and nasal capsule; C) mid-orbit; D) posterior eye; E) temporal region. Abbreviations: Art, articular; Bsph, basisphenoid; CN5, trigeminal nerve; D, dentary; Ect, ectopterygoid; Ept, epipterygoid; Fr, frontal; J, jugal; Mk.C, Meckel's cartilage; Mx, maxilla; N, nasal; P, parietal; Pal, palatine; Pofr, postorbitofrontal; PrA, prearticular; Prfr, prefrontal; Pt, pterygoid; Sur, surangular. Masson Tri-chrome Stain. All scale bars $=250 \mu \mathrm{m}$.

Figure 2. Tarentola annularis. Histological sections through ear region of a late stage 34 (23 dpo) embryo. A) at level of quadrate-articular and quadrate-pterygoid joints; B) at level of tympanic membrane. Abbreviations: Art, articular; CN5, trigeminal nerve; CN8, vestibulocochlear nerve; Es, extrastapes; H, hyoid; m.e, middle ear; Q, quadrate; Pro, prootic; Pt, pterygoid; Tym, tympanic membrane. H\&E stain. Scale bars $=250 \mu \mathrm{m}$.

Figure 3. Tarentola annularis. Late stage 35 (27 dpo) embryo, cleared and stained. A) right lateral view; B) right dorsolateral view of occipital region and suspensorium; C) dorsal view of braincase; D) ventral view of braincase. Abbreviations: Art, articular; c.s., crista sellaris; D, dentary; En, endolymphatic sac; Eo, exoccipital/occipital arch; Ept, epipterygoid; Fr, frontal; H, hyoid; Ic, intercalary cartilage; Mk.C, Meckel's cartilage; Mx, maxilla; Op, opisthotic; P, parietal; PDB, postdentary bones; Pofr, postorbitofrontal; PrO, prootic; Q, quadrate; Sq, squamosal; T.s, intercapsular plate/tectum synoticum; *, 'fenestra X'. Scale bars $=1 \mathrm{~mm}$.

Figure 4. Tarentola annularis. Early (31 dpo, A-B) and mid (33 dpo, C-E) stage 36 embryo, cleared and stained. A) right ventrolateral view; B) dorsal view of orbital region; C) left dorsolateral view; D) right ventrolateral view of symphysial region; E) detail of right postorbital region. Abbreviations: Art, articular; Bc.f, basicranial fenestra; $\mathrm{Ch}$, chondrocranial bars; D.s, dentary symphysis; Eg, egg teeth; En, endolymphatic sac; En. pr, entoglossal process; Ept, epipterygoid; Fr, frontal; H, hyoid; Mk.C, Meckel's 
cartilage; Mx, maxilla; P, parietal; P.f, pituitary fenestra; Pmx, premaxilla; Pofr, postorbitofrontal; P.pr, paroccipital process; PrO, prootic; Q, quadrate; Rap, retroarticular process; Sq, squamosal; t.c., trabeculae cranii. Scale bars $=1 \mathrm{~mm}$.

Figure 5. Tarentola annularis. Early (34 dpo, A-C) and mid (36 dpo, D-F) stage 37 embryo, cleared and stained. A) left ventrolateral view; B) dorsal view of occipital region; C) detail of left suspensorium; D) right lateral view; E) dorsal view; F) right ventrolateral view of rostrum. Abbreviations: a.pr, alary process; Art, articular; Bc.f, basicranial fenestra; Ch, chondrocranial bars; Co, coronoid; D.s, dentary symphysis; D.t, dentary teeth; Eg, egg teeth; En, endolymphatic sac; En. pr, entoglossal process; Eo, exoccipital; Ept, epipterygoid; Fr, frontal; H, hyoid; Ic, intercalary cartilage; Mk.C, Meckel's cartilage; Mx, maxilla; Op, opisthotic; P, parietal; P.f, pituitary fenestra; Pmx, premaxilla; Pofr, postorbitofrontal; P.pr, paroccipital process; Prfr, prefrontal; PrO, prootic; Pt, pterygoid; Q, quadrate; Rap, retroarticular process; So, supraoccipital; Sp, splenial; Sq, squamosal; t.c., trabeculae cranii; T.s, intercapsular plate/tectum synoticum. Scale bars $=1 \mathrm{~mm}$.

Figure 6. Tarentola annularis. Early stage 38 (41 dpo) embryo, cleared and stained. A) left lateral view; B) dorsal view of occipital region; C) right ventrolateral view of hyoid region; D) left ventrolateral view of rostrum. Abbreviations: a.pr, alary process; CB1, 2, ceratobranchials 1,2; CH, ceratohyal; Co, coronoid; Cr, cricoid cartilage; D, dentary; D.t, dentary teeth; Eg, egg teeth; En, endolymphatic sac; Ept, epipterygoid; Mk.C, Meckel's cartilage; Mx. t, maxillary teeth; P, parietal; Pmx, premaxilla; P.pr, paroccipital process; Prfr, prefrontal; PrO, prootic; Pt, pterygoid; Q, quadrate; So, supraoccipital; Sq, squamosal. Scale bars $=1 \mathrm{~mm}$.

Figure 7. Tarentola annularis. Mid stage 38 (44 dpo) embryo, cleared and stained. A) left lateral view; B) left dorsolateral view of suspensorium; C) ventral view; D) dorsal view of occipital region. Abbreviations: a.pr, alary process; At, atlas arch; CB1, 2, ceratobranchials 1,2; CH, ceratohyal; Co, coronoid; D, dentary; D.s, dentary symphysis; 
Eb, epibranchial; Eg, egg teeth; En, endolymphatic sac; En.pr, entoglossal process; Ept, epipterygoid; Ic, intercalary cartilage; Mx, maxilla; P, parietal; Pofr, postorbitofrontal; P.pr, paroccipital process; Q, quadrate; Rap, retroarticular process; So, supraoccipital; Sq, squamosal. Scale bars $=1 \mathrm{~mm}$.

Figure 8. Tarentola annularis. Late stage 38 (48 dpo) embryo, cleared and stained. A) dorsal view; B, left lateral view; $\mathrm{C}$, ventral view of symphysial region. Abbreviations: Bsph, basisphenoid; D.s, dentary symphysis; Fr, frontal; m.b, bulge of adductor muscles; Mx, maxilla; N, nasal; P, parietal; Pmx, premaxilla; $\mathrm{Pmx}+\mathrm{Eg}$, premaxilla with implanted egg teeth; So, supraoccipital. Scale bars $=1 \mathrm{~mm}$.

Figure 9. Tarentola annularis. Late stage 38 (51 dpo) embryo, cleared and stained. A) right lateral view; B, dorsal view; C, ventral view. Abbreviations; m.b., bulge of adductor muscles. Scale bars $=1 \mathrm{~mm}$.

Figure 10. Tarentola annularis. Late stage 39 (61 dpo) embryo, cleared and stained. A, dorsal view of the posterior skull, showing the extensive endolymphatic sacs; $\mathrm{B}$, left lateral view; C, ventral view; D, dorsal view. Abbreviations: Eg, egg teeth; En, endolymphatic sac; m.b, muscle bulge; P, parietal; P.font, parietal fontanelle; P.pr, paroccipital process; Rap, Sq, squamosal. Scale bars $=1 \mathrm{~mm}$.

\section{Tables}

Table 1: Comparison of Dufaure and Hubert (1961) stages at which ossification of individual skull bones commences in different squamates, including Tarentola annularis. Data from: Werneberg et al. (2015, Varanus panoptes); Ollonen et al. (2018, Pogona vitticeps); Abdala et al. (1997, Liolaemus quilmes); Rieppel (1994, Lacerta agilis); Hernandez-Jaimes et al. (2012, Ptychoglossus bicolor), Jerez et al. (2015, Mabuya sp.). 


$\begin{array}{rrrrrrrr} & \text { Tarentola } & \text { Mabuya } & \text { Lacerta } & \text { Ptychoglossus } & \text { Varanus } & \text { Pogona } & \text { Liolaemus } \\ \text { Nasal } & 34 & 39 & 35 & 39 & 38 & 37 & 34 \\ \text { Frontal } & 34 & 34 & 35 & 39 & 36 & 37 & 34 \\ \text { Parietal } & 34 & 34 & 35 & 39 & 36 & 36 & 34 \\ \text { Premaxilla } & 34 & 39 & 35 & 39 & 36 & 37 & 34\end{array}$

39 


\begin{tabular}{|c|c|c|c|c|c|c|c|}
\hline Maxilla & 34 & 39 & 35 & 35 & 36 & 37 & 34 \\
\hline Prefrontal & 34 & 34 & 35 & 35 & 36 & 37 & 34 \\
\hline Postorbitofrontal & 34 & 39 & 35 & 39 & 36 & 37 & 35 \\
\hline Jugal & 34 & 39 & 34 & 35 & 36 & 36 & 34 \\
\hline Squamosal & 35 & 39 & 35 & 39 & 36 & 36 & 34 \\
\hline Epipterygoid & 34 & 39 & 35 & $39 / 40$ & 38 & 38 & 35 \\
\hline Quadrate & 34 & 39 & 35 & $39 / 40$ & 38 & 38 & 34 \\
\hline Vomer & 34 & 39 & 35 & 39 & 36 & 37 & 35 \\
\hline Palatine & 34 & 34 & 34 & 39 & 35 & 36 & 34 \\
\hline Pterygoid & 34 & 32 & 34 & 35 & 35 & 34 & 33 \\
\hline Ectopterygoid & 34 & 39 & 35 & 39 & 36 & 37 & 34 \\
\hline Septomaxilla & 34 & $?$ & $?$ & $?$ & 36 & 38 & 34 \\
\hline Basisphenoid & 34 & 39 & 35 & 39 & 38 & 37 & 35 \\
\hline Basioccipital & 35 & 39 & 35 & 39 & 38 & 38 & 35 \\
\hline Parasphenoid & 35 & 39 & $?$ & 39 & 38 & 38 & 35 \\
\hline Opisthotic & 35 & 40 & 37 & 39 & 38 & 38 & 35 \\
\hline Prootic & 35 & 40 & 37 & 39 & 38 & 39 & 35 \\
\hline Exoccipital & 35 & 40 & 35 & 39 & 38 & 37 & 34 \\
\hline Supraoccipital & 35 & 40 & 37 & 39 & 38 & 38 & 35 \\
\hline Stapes & 35 & $?$ & $?$ & $?$ & 39 & 38 & 35 \\
\hline Dentary & 34 & 33 & 35 & $39 / 40$ & 36 & 36 & 33 \\
\hline Angular & $?$ & 39 & 35 & $39 / 40$ & 36 & 37 & 34 \\
\hline Surangular & 34 & 34 & 34 & $39 / 40$ & 35 & 36 & 33 \\
\hline Coronoid & 35 & 39 & 35 & 39 & 36 & 37 & 34 \\
\hline Splenial & 35 & 39 & 35 & $39 / 40$ & 36 & 37 & 34 \\
\hline Articular & 35 & 39 & 35 & $39 / 40$ & 36 & 38 & 35 \\
\hline Prearticular & 34 & 39 & 34 & $39 / 40$ & 36 & 37 & 4 \\
\hline
\end{tabular}

Table 1. Comparison of stages at which ossification of individual skull bones commences in different squamates (references for individual taxa are listed in the text). 
